\section{Molecular and Cellular Biology}

Simian virus 40 DNA replication in vitro: identification of multiple stages of initiation.

T Tsurimoto, M P Fairman and B Stillman

Mol. Cell. Biol. 1989, 9(9):3839. DOI: 10.1128/MCB.9.9.3839.

Updated information and services can be found at:

http://mcb.asm.org/content/9/9/3839

These include:

CONTENT ALERTS

Receive: RSS Feeds, eTOCs, free email alerts (when new articles cite this article), more» 


\title{
Simian Virus 40 DNA Replication In Vitro: Identification of Multiple Stages of Initiation
}

\author{
TOSHIKI TSURIMOTO, MICAELA P. FAIRMAN, $†$ AND BRUCE STILLMAN* \\ Cold Spring Harbor Laboratory, P.O. Box 100, Cold Spring Harbor, New York 11724
}

Received 27 February 1989/Accepted 8 June 1989

\begin{abstract}
A cell-free DNA replication system dependent upon five purified cellular proteins, one crude cellular fraction, and the simian virus 40 (SV40)-encoded large tumor antigen ( $T$ antigen) initiated and completed replication of plasmids containing the SV40 origin sequence. DNA synthesis initiated at or near the origin sequence after a time lag of approximately $10 \mathrm{~min}$ and then proceeded bidirectionally from the origin to yield covalently closed, monomer daughter molecules. The time lag could be completely eliminated by a preincubation of SV40 ori DNA in the presence of $T$ antigen, a eucaryotic single-stranded DNA-binding protein (replication factor A [RF-A]), and topoisomerases I and II. In contrast, if T antigen and the template DNA were incubated alone, the time lag was only partially decreased. Kinetic analyses of origin recognition by $T$ antigen, origin unwinding, and DNA synthesis suggest that the time lag in replication was due to the formation of a complex between $T$ antigen and DNA called the $T$ complex, followed by formation of a second complex called the unwound complex. Formation of the unwound complex required RF-A. When origin unwinding was coupled to DNA replication by the addition of a partially purified cellular fraction (IIA), DNA synthesis initiated at the ori sequence, but the template DNA was not completely replicated. Complete DNA replication in this system required the proliferating-cell nuclear antigen and another cellular replication factor, RF-C, during the elongation stage. In a less fractionated system, another cellular fraction, SSI, was previously shown to be necessary for reconstitution of DNA replication. The SSI fraction was required in the less purified system to antagonize the inhibitory action of another cellular protein(s). This inhibitor specifically blocked the earliest stage of DNA replication, but not the later stages. The implications of these results for the mechanisms of initiation and elongation of DNA replication are discussed.
\end{abstract}

DNA replication is one of the prominent events in the eucaryotic cell cycle and is highly regulated to allow only one round of DNA synthesis during each $\mathrm{S}$ phase. To elucidate the mechanism and regulation of DNA replication in higher eucaryotes, biochemical studies are necessary, since the use of a genetic approach in mammalian cells is difficult. The development of a vigorous cell-free system that supports complete replication of simian virus 40 (SV40) origin-containing plasmids $(27,28,46,51)$ has made SV40 a useful model for the study of DNA replication in mammalian cells. The cell-free system consists of a soluble extract from human cells, purified $\mathrm{T}$ antigen, and template DNAs that contain the SV40 origin of DNA replication. DNA replication in vitro proceeds bidirectionally from the origin in a manner similar to the proposed mode of eucaryotic chromosomal replication (15). Since $T$ antigen is the only virusencoded protein required, replication is for the most part dependent upon the cellular replication machinery. Thus, it is expected that studying the replication of SV40 DNA in vitro will advance our knowledge of cellular DNA replication.

To identify and characterize the cellular proteins that are required for SV40 DNA replication in vitro, we and others have fractionated an extract from human cells and identified seven cellular components that are necessary to completely replicate plasmids containing the SV40 origin region $(19,20$, $32,36,44,48,52,53,56)$. Kinetic analyses of SV40 DNA replication in vitro and the deduced function of the replica-

\footnotetext{
* Corresponding author.

$\dagger$ Present address: CRC Molecular Embryology Group, Department of Zoology, Cambridge University, Cambridge CB2 3EJ, United Kingdom.
}

tion components has led to the definition of multiple stages of replication. This replication system has a characteristic time lag of 10 to 15 min prior to the start of DNA synthesis, owing to the interaction of replication proteins with the origin $(45,50,54)$. During this presynthesis stage, the first step is the ATP-dependent binding of T antigen to the SV40 origin core sequence $(4,5,14)$, which results in formation of specialized nucleoprotein complex at the origin (13). In the presence of a single-strand DNA-binding protein, (either from Escherichia coli or from human cells) and topoisomerase, but in the absence of DNA synthesis, the template DNA is extensively unwound by the helicase activity of $T$ antigen $(12,16,21,43,49,53,54)$ to yield a highly underwound molecule known as form $\mathrm{U}$. Form $\mathrm{U}$ is a by-product of the early origin-unwinding events and occurs in the absence of DNA replication. A cellular fraction (SSI) is also required for SV40 DNA replication in vitro in a crude system and is required during the presynthesis stage $(19,20)$. Another cellular fraction (IIA), which contains DNA polymerases and other activities is required for initiation of DNA replication at the origin and for subsequent DNA synthesis (48).

Two purified cellular proteins, the proliferating-cell nuclear antigen (PCNA) and replication factor C (RF-C), are required for coordinated synthesis of leading and lagging DNA strands during the elongation stage of replication (36, 48). Studies of the elongation mode of DNA replication in procaryotic systems have demonstrated that once DNA synthesis initiates at a unique site (replication origin), replication at a fork proceeds semidiscontinuously, during which the leading strand is synthesized continuously while the lagging strand is synthesized discontinuously via Okazaki fragment intermediates $(1,23,31,33,34)$. On the basis of the discovery that PCNA is an auxiliary protein for DNA 
polymerase $\delta(9,11,35,47)$ and that it is required for normal leading-strand DNA synthesis during SV40 replication in vitro (37), a model for the eucaryotic replication fork was proposed. In this model, two functionally distinct DNA polymerases, $\alpha$ and $\delta$, form a multiprotein complex with other proteins at a replication fork to synthesize leading and lagging strands coordinately $(18,37,42,44)$.

The multiple stages of SV40 DNA replication in vitro may reflect similar stages of DNA replication in the host cell, and each step might be a target for cell cycle control or temporal regulation of DNA replication from multiple chromosomal origins throughout the $\mathrm{S}$ phase. For example, PCNA, which was alternatively known as either cyclin or the polymerase $\delta$ auxiliary protein, is a well-studied, cell-cycle-regulated protein that also appears to be required for cellular DNA replication (57; M. B. Mathews, in H. R. Warner and E. Wang, ed., Growth Control during Cell Aging, in press). Its omission from the reconstituted SV40 system results in accumulation of abnormal early replicative intermediates, suggesting that PCNA may play some role in the assembly of elongation complexes following initiation at the replication origin (37). It is difficult, however, to precisely determine the relationship between the function of a protein and its involvement in any stage of replication with crude fractions. In this paper we describe the reconstitution of SV40 replication with six purified proteins together with a partially purified, multicomponent fraction. This reconstituted replication system can reproduce most of the features previously described for cruder systems. Using this sytem, we identified cellular components that influence the presynthesis stage of SV40 DNA replication in vitro, and we propose a model for the multiple stages of initiation.

\section{MATERIALS AND METHODS}

Plasmid and bacteriophage DNAs. The plasmid DNAs (37) used as templates in replication reactions were pSVO10, which contains the entire SV40 genome in pUC18 and is 7.9 kilobase pairs in size; pSVO11, which contains the SV40 origin fragment from HindIII (nucleotide nt 5171) to SphI (nucleotide 128) in pUC18 and is 2.9 kilobase pairs in size; and pSVO2, which contains the entire SV40 genome in pAT153 and was used for the hybridization study, since this plasmid has no homology with the M13-SV40 hybrid probe DNAs except for the SV40 sequence. Single-stranded bacteriophage DNAs were prepared from six M13-SV40 hybrid clones described previously (37).

Preparation of components used in the reconstituted replication reaction. Cytosol extracts and high-speed supernatants (S100) were prepared from 16 liters of human 293 cells $\left(8 \times 10^{9}\right.$ cells $)$ in suspension as previously described $(27,46)$. The S100 fraction was adjusted to $0.2 \mathrm{M} \mathrm{NaCl}$ and loaded onto a phosphocellulose column $(2.5$ by $10 \mathrm{~cm})$ that had been equilibrated in buffer A ( $25 \mathrm{mM}$ Tris hydrochloride [ $\mathrm{pH} 7.5$ ], $1 \mathrm{mM}$ disodium EDTA, $0.1 \mathrm{mM}$ phenylmethylsulfonyl fluoride, $0.01 \%$ Nonidet $\mathrm{P}-40,1 \mathrm{mM}$ dithiothreitol, $10 \%$ glycerol) containing $0.2 \mathrm{M} \mathrm{NaCl}$. Fractions I, IIA, IIB, IIC, and IID were obtained by successive washes with $100 \mathrm{ml}$ of buffer $A$ containing $0.2,0.33,0.4,0.6$, and $1.0 \mathrm{M} \mathrm{NaCl}$, respectively $(36,48)$. These fractions were dialyzed against buffer A containing $0.025 \mathrm{M} \mathrm{NaCl}$ and $20 \%$ sucrose and used in the replication assay or for further fractionation. Protein concentrations of fraction IIA and IID were 5 and $4 \mathrm{mg} / \mathrm{ml}$, respectively.

A crude fraction (SS1, $44 \mathrm{mg}$ of protein per $\mathrm{ml}$ ) and a purified activity (RF-A) were obtained from fraction I by
DEAE-cellulose column chromatography and ammonium sulfate precipitation, followed by chromatography on denatured DNA-cellulose and a second DEAE-cellulose column as described previously (20). PCNA from fraction I was purified by successive chromatographic steps through DEAE-cellulose, phenyl-Sepharose, and Mono-Q columns, followed by a final glycerol gradient centrifugation step as described previously (36). RF-C was purified from a 293 cell nuclear extract as described before (48). In short, a phosphocellulose fraction from the nuclear extract (equivalent to fraction IIC) was prepared and then purified by chromatography on hydroxylapatite, a second phosphocellulose, and denatured DNA-cellulose columns. Topoisomerases I and II were prepared from a calf thymus nuclear extract by slight modifications of published procedures $(29,40)$. These purified components are almost homogeneous (see Fig. 1).

Replication reaction with six cellular components. In the complete system, replication from the origin of SV40 DNA replication in vitro was assayed under standard conditions $(50-\mu$ l reaction mixture) as described previously (46), with $300 \mathrm{ng}$ of template DNA and optimum amounts of purified SV40 T antigen (1.0 to $1.5 \mu \mathrm{g}), 300 \mathrm{ng}$ of RF-A, 100 to $150 \mathrm{ng}$ of PCNA, $100 \mathrm{ng}$ of RF-C, $200 \mathrm{ng}$ of topoisomerase I, $90 \mathrm{ng}$ of topoisomerase II, and $20 \mu \mathrm{g}$ of fraction IIA for $1 \mathrm{~h}$ at $37^{\circ} \mathrm{C}$. Reactions were terminated with $10 \mathrm{mM}$ disodium EDTA, and acid-insoluble counts were measured.

SV40 $\mathrm{T}$ antigen. SV40 large $\mathrm{T}$ antigen was obtained from recombinant adenovirus-infected human cells as described previously (46) or, more recently, from recombinant baculovirus vector (941T)-infected Spodotera frugiperda insect cells as described by Lanford (25). T antigen was purified by the procedure of Simanis and Lane (41). The specific activity for DNA replication of the baculovirus-expressed $T$ antigen was twice that of the T antigen produced in HeLa cells (B. Stillman, Y. Gluzman, and I. Mohr, unpublished results).

Product analysis. To analyze the replication products, the reaction mixture containing the indicated amount of each component was incubated at $37^{\circ} \mathrm{C}$, the reaction was terminated at the indicated time by mixing with an equal volume of proteinase $\mathrm{K}$ solution $(0.2 \mathrm{mg}$ of proteinase $\mathrm{K}$ per $\mathrm{ml}, 2 \%$ sodium dodecyl sulfate, $20 \mathrm{mM}$ disodium EDTA), and the sample was further incubated at $37^{\circ} \mathrm{C}$ for $1 \mathrm{~h}$. DNA in the reaction mixture was extracted with phenol-chloroform (1: 1), precipitated with ethanol, and dissolved in $20 \mu \mathrm{l}$ of $10 \mathrm{mM}$ Tris hydrochloride ( $\mathrm{pH}$ 7.4)-1 mM disodium EDTA (TE). A portion of the sample was subjected to electrophoresis in a neutral agarose gel $(0.8 \%)$ in Tris-borate-EDTA buffer (TBE [30]) at $2.5 \mathrm{~V} / \mathrm{cm}$ for $10 \mathrm{~h}$, in an alkaline agarose gel (1\%) in $30 \mathrm{mM} \mathrm{NaOH}-1 \mathrm{mM}$ disodium EDTA at $1.5 \mathrm{~V} / \mathrm{cm}$ for $12 \mathrm{~h}$, or in a polyacrylamide gel $(6 \%)$ in TBE following digestion with restriction enzymes. Before being dried for autoradiography, the gels were fixed in $10 \%$ methanol-10\% acetic acid.

DNA-unwinding assay. The reaction mixture contained 40 mM $N$-2-hydroxyethylpiperazine- $N^{\prime}$-2-ethanesulfonic acid (HEPES)-KOH (pH 7.5), $8 \mathrm{mM} \mathrm{MgCl}_{2}, 0.5 \mathrm{mM}$ dithiothreitol, $4 \mathrm{mM}$ ATP, $40 \mathrm{mM}$ creatine phosphate, $20 \mu \mathrm{g}$ of creatine phosphokinase per $\mathrm{ml}, 0.1 \mathrm{mg}$ of bovine serum albumin per $\mathrm{ml}, 4 \mu \mathrm{g}$ of calf thymus topoisomerase I per $\mathrm{ml}$, $7.5 \mu \mathrm{g}$ of RF-A per ml, $6 \mu \mathrm{g}$ of pSVO11 DNA per ml, and 20 $\mu \mathrm{g}$ of $\mathrm{T}$ antigen per $\mathrm{ml}$. The reaction mixture was incubated at $37^{\circ} \mathrm{C}$ for the indicated time, and the reaction was terminated by addition of sodium dodecyl sulfate and EDTA (final concentrations, $1 \%$ and $10 \mathrm{mM}$, respectively). The mixture was incubated with RNase A $(10 \mu \mathrm{g} / \mathrm{ml})$ and protease XIII $\left(50 \mu \mathrm{g} / \mathrm{ml}\right.$; Sigma Chemical Co.) at $37^{\circ} \mathrm{C}$ for $30 \mathrm{~min}$. The DNA in the sample was extracted with phenol-chloroform 


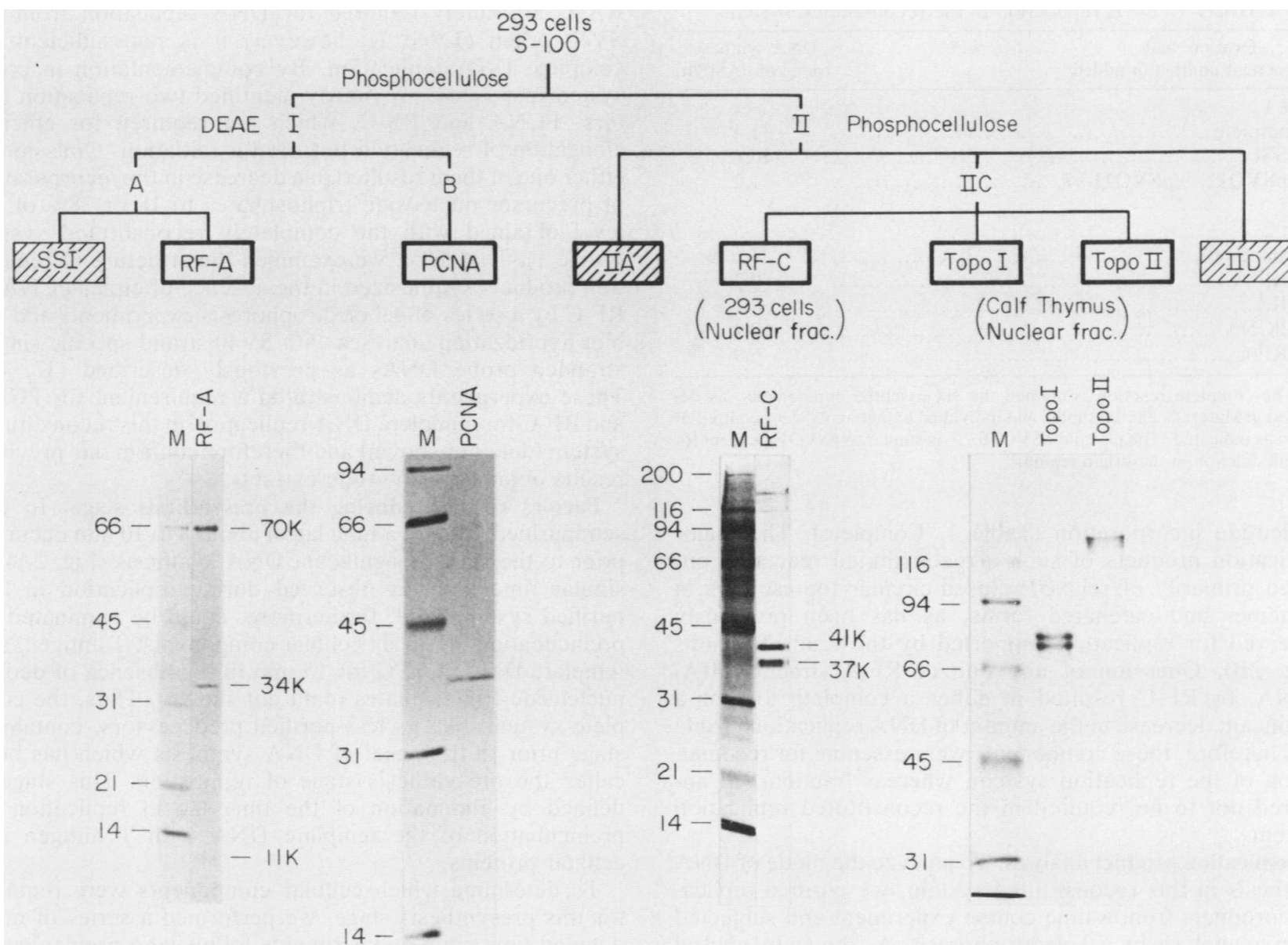

FIG. 1. An S100 extract from 293 cells was divided into multiple fractions by phosphocellulose chromatography and fractionated further to purify replication components. Preparation of fractions I, IA, and IB and the purification of PCNA were previously described (36). The preparation of fraction SSI and of the purified replication factor RF-A was described by Fairman and Stillman (20). The preparation of fractions IIA, IIC, and IID and the purification of RF-C were described by Tsurimoto and Stillman (48). Components boxed in bold are the six essential components for replication from the SV40 origin and were used in the complete reaction (see text). The other two are the inhibitor (IID) and its antagonist (SSI). Components which have not been purified are shaded. RF-C is normally purified from a 293 cell nuclear extract, and topoisomerases (Topo) are normally isolated from calf thymus nuclei. Shown below them are samples of purified factors RF-A, PCNA, RF-C, and topoisomerases I and II after separation by sodium dodecyl sulfate-polyacrylamide gel electrophoresis and detection by either silver staining (for RF-A and RF-C) or Coomassie brilliant blue staining (for PCNA and topoisomerases I and II). The molecular masses of marker polypeptides (in kilodaltons) are shown on the left of each panel, and the molecular masses of some of the replication proteins are shown on the right.

(1:1), precipitated with ethanol, subjected to agarose gel electrophoresis in TBE buffer, and visualized by staining with ethidium bromide.

Protein analysis. Proteins were separated by sodium dodecyl sulfate-polyacrylamide gel electrophoresis as previously described (24) and were stained with silver by a slight modification of the method of Wray et al. (55) or with Coomassie brilliant blue. Protein concentrations were determined by the method of Bradford (6), with bovine serum albumin as a standard.

\section{RESULTS}

Fractionation and reconstitution of SV40 replication components. As described previously $(20,36,48)$, the cytoplasmic extract (S100) derived from human 293 cells was divided by phosphocellulose chromatography into multiple fractions (Fig. 1). Following further fractionation, five purified factors, RF-A, PCNA, RF-C, and topoisomerases I and II, were shown to be essential for the production of completely replicated daughter molecules from a closed-circular template DNA. In addition, two fractions, SSI and IIA, which still contain nonpurified components, were required for SV40 replication in vitro. In our previous studies, the participation of these purified proteins or partially purified components in SV40 replication in vitro was demonstrated by reconstitution of replication by using crude fractions and only one purified protein $(20,36,48)$. It was important, therefore, to determine whether the replication reaction could be reconstituted when these isolated components were combined and, if so, whether they were essential.

Replication reactions containing all seven cellular components (RF-A, PCNA, RF-C, topoisomerases I and II, and fractions IIA and SSI) were able to support the replication of SV40 origin-containing plasmids, although a relatively low level of nucleotide incorporation was obtained (Table 1, Complete + SSI). Unexpectedly, replication reactions lacking fraction SSI, but containing the other six components, yielded about twofold-higher levels of SV40 ori-dependent 
TABLE 1. DNA replication in the reconstituted system

\begin{tabular}{|c|c|}
\hline $\begin{array}{l}\text { Expt no. and } \\
\text { component omitted or added } \\
\end{array}$ & $\begin{array}{l}\text { DNA synthesis } \\
\text { (pmol of dAMP/h) }\end{array}$ \\
\hline \multicolumn{2}{|l|}{ Expt 1} \\
\hline Complete.. & 31.4 \\
\hline+ SSI .......... & 16.6 \\
\hline- pSVO11, +pSVO11ori ${ }^{-}$........................... & 1.2 \\
\hline \multicolumn{2}{|l|}{ Expt 2} \\
\hline (2) & 37.6 \\
\hline …........................... & 0.2 \\
\hline -IIA & 0.5 \\
\hline 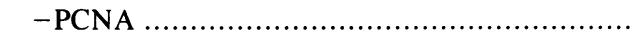 & 10.4 \\
\hline 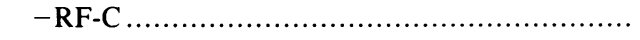 & 6.9 \\
\hline
\end{tabular}

${ }^{a}$ The complete reaction contained the six essential components, as described in Materials and Methods, and individual components were omitted or added as indicated. The plasmid pSVO11 ori $^{-}$is similar to pSVO11, except for a small deletion in the origin region.

nucleotide incorporation (Table 1, Complete). The major replication products of such a reconstituted reaction consisted primarily of relaxed, closed-circular topoisomers in monomer and catenated forms, as has been previously observed for replication supported by the crude fractions (Fig. 2B). Omission of any one of RF-A, fraction IIA, PCNA, or RF-C resulted in either a complete loss or a significant decrease in the amount of DNA replication (Table 1). Therefore, these components were essential for reconstitution of the replication system, whereas fraction SSI appeared not to be required in the reconstituted replication system.

Replication product analysis. To analyze the mode of DNA synthesis in this reconstituted system, we purified replication products from a time course experiment and subjected them to analysis by gel electrophoresis. As shown by neutral agarose gel electrophoresis (Fig. 2B), molecules migrating slightly more slowly than forms I and II marker DNA were observed at the earliest time point and corresponded to very early replicative intermediates (37). Following a longer incubation of the reaction mixture, the product changed to a smear of higher-molecular-weight species, corresponding to the distribution of Cairns- $\theta$ structures. Finally, after about 12 to $16 \mathrm{~min}$, mature monomer daughter molecules (various topological isomers) and a small number of catenated molecules were produced. This product analysis is completely consistent with the replicative products obtained by using less-fractionated extracts $(37,48)$ and with the known mechanism of SV40 DNA replication in vivo (15). Alkaline agarose gel electrophoresis of the same products revealed a bimodal smear of single-stranded DNA at early time points and the accumulation of full-length linear and closed-circular DNA at later times (Fig. 2C). The bimodal smear of replication products may represent the synthesis of leading-strand (long) and lagging-strand Okazaki (short) fragments during the elongation phase of the reaction.

The isolated replication products from this time course were also digested with restriction enzymes and subjected to polyacrylamide gel electrophoresis (Fig. 2D). At the early times, the two origin-containing fragments were labeled, followed by the origin-proximal fragments, and finally, at later times, the origin-distal fragments replicated. In addition, the replication in this population of molecules was bidirectional from the origin, as shown previously with crude extracts $(28,46,51)$.

PCNA and RF-C are required for coordinated leading and lagging DNA synthesis in the reconstituted system. Fraction
IIA is absolutely required for DNA replication from the SV40 origin (Table 1); however, it is not sufficient for complete DNA replication. By complementation in crude systems, we have previously identified two replication factors, PCNA and RF-C, which are required for efficient elongation of replication but not for initiation. Omission of either one of them resulted in a decrease in the incorporation of precursor nucleoside triphosphates to 18 or $28 \%$ of the level obtained with the completely reconstituted system (Table 1). Therefore, we examined the structure of replication products synthesized in the absence of either PCNA or RF-C by a series of gel electrophoresis experiments and dot blot hybridzation analyses with SV40 strand-specific singlestranded probe DNAs as previously described (37, 48). These experiments demonstrated a requirement for PCNA and $\mathrm{RF}-\mathrm{C}$ for complete DNA replication in this reconstituted system (data not shown) and therefore confirm our previous results obtained with crude extracts.

Factors required during the presynthesis stage. In this semipurified system, a time lag of about 8 to $10 \mathrm{~min}$ occurred prior to the start of significant DNA synthesis (Fig. 2A). A similar time lag was observed during replication in less purified systems and, furthermore, could be eliminated by preincubation of the six cellular components, $\mathrm{T}$ antigen, and template DNA at $37^{\circ} \mathrm{C}$ for $15 \mathrm{~min}$ in the absence of deoxynucleoside triphosphates (data not shown). Thus, the complete system, like its less-purified predecessors, contains a stage prior to the onset of DNA synthesis which has been called the presynthesis stage of replication. This stage is defined by elimination of the time lag in replication by preincubation of the template DNA with $T$ antigen and cellular proteins.

To determine which cellular components were required for this presynthesis stage, we performed a series of more detailed time course experiments following a preincubation step (Fig. 3). If the template DNA was preincubated alone for $15 \mathrm{~min}$ at $37^{\circ} \mathrm{C}$ and then all of the protein components were added at time zero, a time lag of approximately $10 \mathrm{~min}$ was observed (as described above and shown in Fig. 2A, when there was no preincubation). On the other hand, if $T$ antigen was included in the preincubation step, the time lag was reduced to approximately $5 \mathrm{~min}$. This reduction in the time lag by preincubation of the template DNA with T antigen is ATP dependent (data not shown). This shorter time lag could be eliminated completely by the addition of RF-A, topoisomerases, and $\mathrm{T}$ antigen during the preincubation step (Fig. 3). Complete elimination of the time lag required RF-A (Fig. 3), but addition of all the other components to the preincubation step, in all combinations including fraction SSI instead of RF-A, had no effect (data not shown). Therefore, the presynthesis reaction in the reconstituted system could be divided into at least two steps, one involving complex formation between the SV40 origin and T antigen and the other involving RF-A also.

Origin-specific unwinding reaction. In the absence of DNA replication, but in the presence of $\mathrm{T}$ antigen, RF-A (or another single-strand DNA-binding protein), and topoisomerases, plasmid DNAs carrying the SV40 ori sequence become extensively unwound. When the protein is removed, the product of the reaction is a highly underwound DNA molecule called form $U$ (12). Form $U$ is detected by agarose gel electrophoresis following deproteinization of the product and migrates slightly more slowly than the form I marker DNA. This molecule is thought to be a by-product of the unwinding process that occurs prior to priming of DNA synthesis at the replication origin $(12,16,54)$. If this is so, 
A

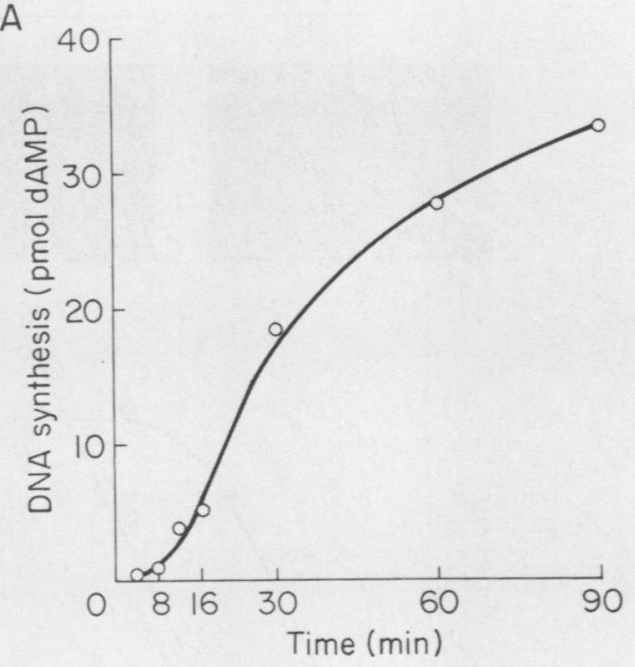

B

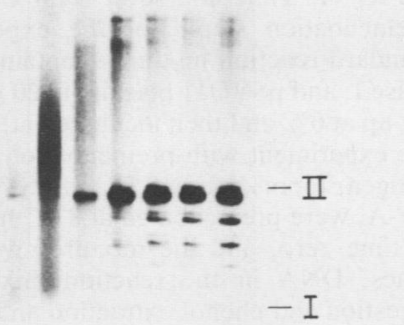

C
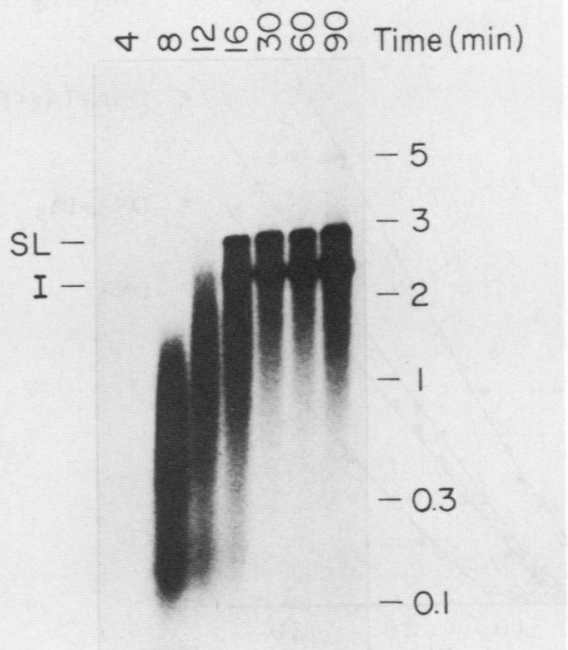

D
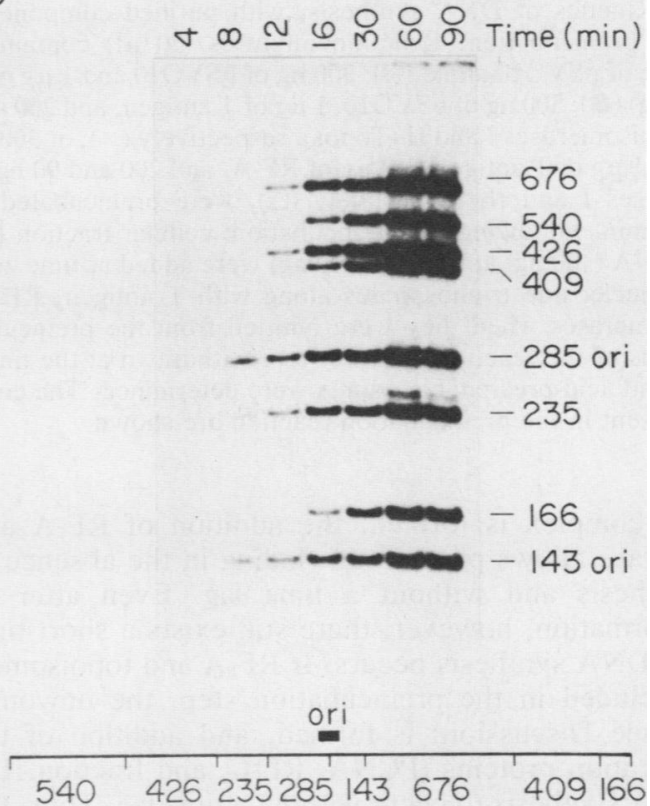

FIG. 2. Kinetic and product analyses of SV40 DNA replication with six cellular components. A reaction mixture with the six essential cellular components and SV40 T antigen (see Materials and Methods) was assembled on ice and incubated at $37^{\circ} \mathrm{C}$. Portions were withdrawn at the indicated times and subjected to trichloroacetic acid precipitation and product analysis. The rate and amount of replication was determined by incorporation of $\left[\alpha-{ }^{32} \mathrm{P}\right] \mathrm{dATP}$ into acid-insoluble counts and expressed as picomoles of dAMP incorporated in a 50- $\mu l$ reaction mixture at each time point (A). Purified replication products containing approximately the same number of counts per lane were loaded directly into a neutral agarose gel (B) or, following denaturation, into an alkaline agarose gel (C) (except for the 4-min samples, in which the counts were about one-fifth those of the other samples and were exposed twice as long [in panel B]). Equal portions of replication products from each of the time points were digested with DdeI and SphI and then subjected to polyacrylamide gel electrophoresis (D). The markers for gel electrophoresis shown next to each gel were forms I and II of the template DNA (pSVO11) (panel B) and denatured DNA fragments obtained from HindIII-digested adenovirus type 2 DNA (the sizes of these fragments are shown in kilobases on the right) (I and SL are denatured form I and single-strand, linear of unit length, respectively) (panel C). The size (in base pairs) of each band is indicated on the right of panel D, and the corresponding map is shown below the autoradiograph. Fragments containing the SV40 replication origin are shown.

the kinetics of production of the unwound form $U$ molecule should closely correlate with the kinetics of one of the two stages of DNA replication just described. We studied the relationship between the two presynthesis steps and production of form $U$ by kinetic experiments with purified proteins (Fig. 4). Production of form U exhibited a time lag of about 4 min without any preincubation step. Preincubation of T antigen and template DNA, followed by addition of RF-A at time zero, eliminated the time lag for form $U$ production. This is analogous to the shift from the full time lag to the reduced time lag shown in Fig. 3.

The kinetic experiments whose results are shown in Fig. 3 and 4 lead to the following conclusions. The time lag prior to the onset of DNA synthesis is a result of multiple events, the first being the ATP-dependent interaction of T antigen with the origin to form a complex ( $T$ complex, see Discussion). 


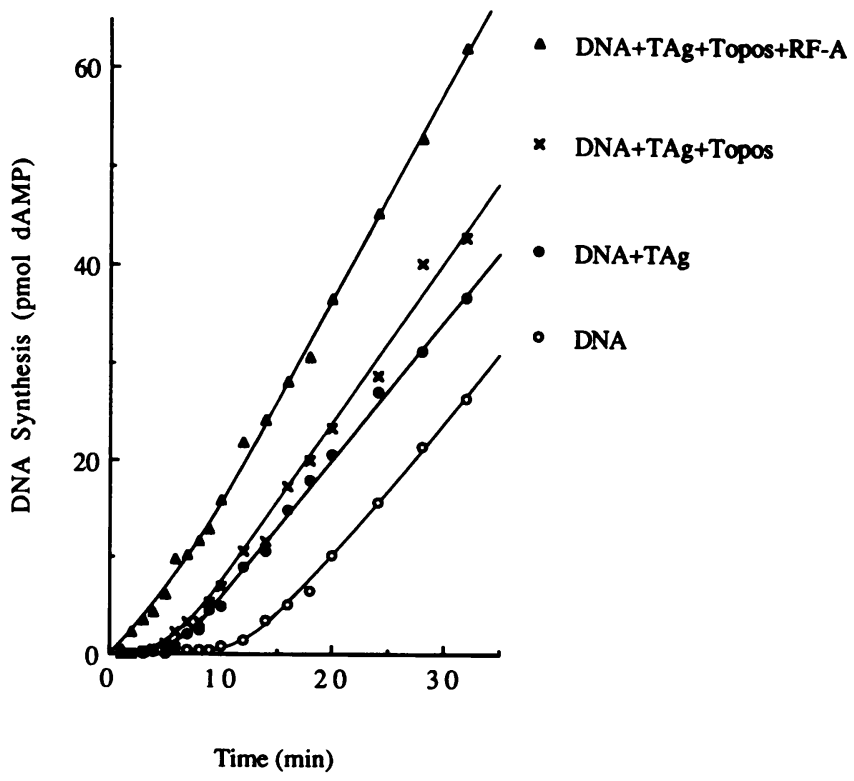

FIG. 3. Kinetics of DNA synthesis, with purified components following a preincubation. Reaction mixtures $(50 \mu \mathrm{l})$ containing either $300 \mathrm{ng}$ of pSVO10 alone (O); $300 \mathrm{ng}$ of pSVO10 and $1 \mu \mathrm{g}$ of T antigen (TAg) (O); $300 \mathrm{ng}$ of pSVO10, $1 \mu \mathrm{g}$ of T antigen, and 200 and $90 \mathrm{ng}$ of topoisomerases I and II (Topos), respectively $(X)$; or $300 \mathrm{ng}$ of pSVO10, $1 \mu \mathrm{g}$ of T antigen, $1.2 \mu \mathrm{g}$ of RF-A, and 200 and $90 \mathrm{ng}$ of topoisomerases I and II, respectively $(\triangle)$, were preincubated at $37^{\circ} \mathrm{C}$ for $15 \mathrm{~min}$. Following the preincubation, cellular fraction IIA $(20 \mu \mathrm{g})$, PCNA (300 $\mathrm{ng})$ and RF-C (100 $\mathrm{ng})$ were added at time zero with deoxynucleoside triphosphates along with $\mathrm{T}$ antigen, RF-A, and topoisomerases when they were omitted from the preincubation. Portions of the reaction mixture were withdrawn at the times indicated, and acid-precipitable counts were determined. The components present in the preincubation reaction are shown.

Once this complex is formed, the addition of RF-A and topoisomerase allows plasmid unwinding in the absence of DNA synthesis and without a time lag. Even after Tcomplex formation, however, there still exists a short time lag before DNA synthesis occurs. If RF-A and topoisomerase are included in the preincubation step, the unwound complex (see Discussion) is formed, and addition of the other replication proteins (PCNA, RF-C, and fraction IIA) allows DNA synthesis to occur without a time lag. Thus, the full lag in replication seems to correspond to the sequential accumulation of the $T$ and unwound complexes, whereas the reduced lag corresponds to the accumulation of the unwound complex. Priming of DNA synthesis on the unwound complex appears to be rapid.

Fraction IID inhibits replication, and fraction SSI neutralizes the inhibition. In previous studies, we have demonstrated a requirement for fraction SSI in SV40 replication in vitro $(19,20)$. We could not, however, demonstrate that this fraction is required in the more highly purified reconstituted system. In the previously reported experiments, fraction II (a phosphocellulose fraction stepped off between 0.2 and $1 \mathrm{M}$ $\mathrm{NaCl}$ ) was used instead of fraction IIA, RF-C, and topoisomerases. This suggested that a factor might exist in fraction II which inhibited replication and which was removed from fraction IIA and RF-C by purification. If this was the case, we might expect fraction SSI to contain a factor(s) that antagonizes the inhibitor. To test this hypothesis, we added fraction IIB, IIC, or IID to the reconstituted reaction containing the six essential cellular components and $\mathrm{T}$ antigen.

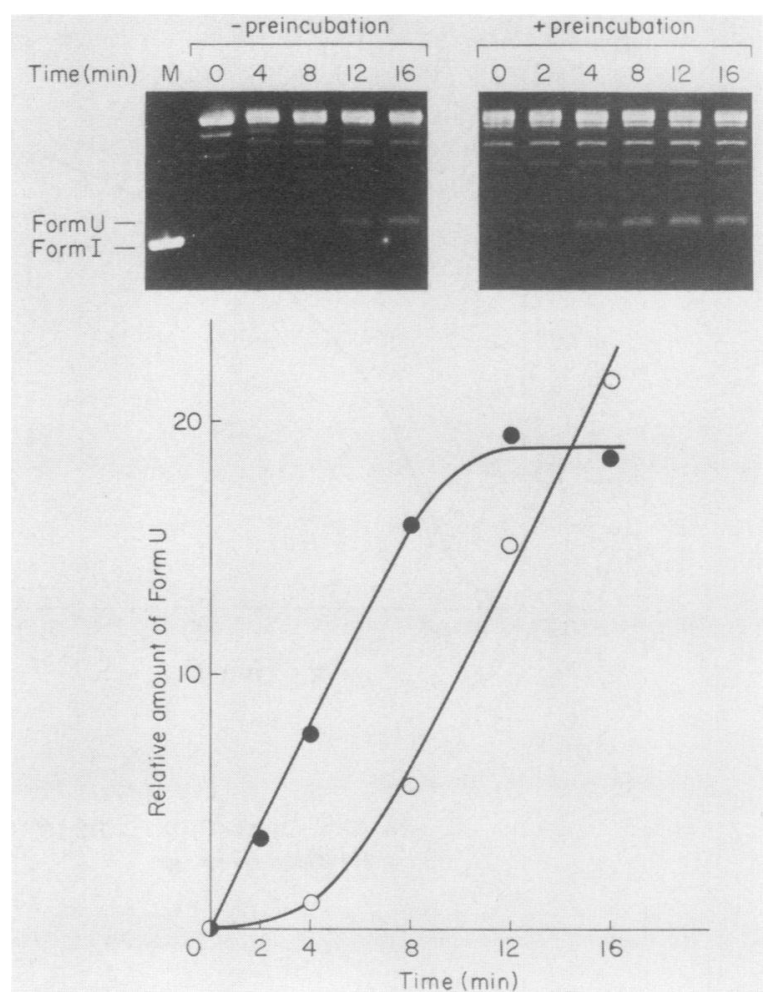

FIG. 4. Time course of form $U$ production with and without a preincubation step. For the experiment without preincubation, standard reaction mixtures containing $\mathrm{T}$ antigen, RF-A, topoisomerase I, and pSVO11 plasmid in $20 \mu \mathrm{l}$ (Materials and Methods) were set up at $0^{\circ} \mathrm{C}$ and then incubated at $37^{\circ} \mathrm{C}$ for the indicated times. For the experiment with preincubation, reaction mixtures containing $\mathrm{T}$ antigen, topoisomerase I, and pSVO11 plasmid DNA, but without RF-A, were preincubated at $37^{\circ} \mathrm{C}$ for $15 \mathrm{~min}$. RF-A was then added at time zero, and the mixtures were incubated for the indicated times. DNA in the reaction mixture was isolated by protease digestion and phenol extraction and loaded into a $0.8 \%$ agarose gel. It was visualized by staining with ethidium bromide. The amount of form $U$ was estimated by densitometric tracing of the bands on a negative of the photograph and plotted as their relative intensity for each time point. Symbols: $\bigcirc$, reactions without a preincubation; $\bullet$, reactions with a preincubation.

Fraction IID indeed inhibited replication completely (Fig. 5), whereas fractions IIB and IIC had no additional inhibitory effect on replication (data not shown). Moreover, addition of fraction SSI could neutralize the inhibition by fraction IID, as was predicted. In this case, the replication product obtained in the presence of SSI and IID was exactly the same as that obtained when the complete system was used.

Fraction IID inhibits T-complex formation. DNA replication reactions containing fraction IID did not yield any detectable products (Fig. 5, lane 2); therefore, the inhibition was not the same as the replication block obtained in the absence of PCNA or RF-C but appeared to be the result of a block in initiation of DNA synthesis. Furthermore, previous results indicated that fraction SSI affected the presynthesis stage of DNA replication (20). These results implied that both inhibition by fraction IID and neutralization by fraction SSI would involve one step in the presynthesis stage of replication.

As described above, kinetic experiments could distinguish between two stages that occur prior to the onset of DNA synthesis. Therefore, time course experiments were per- 


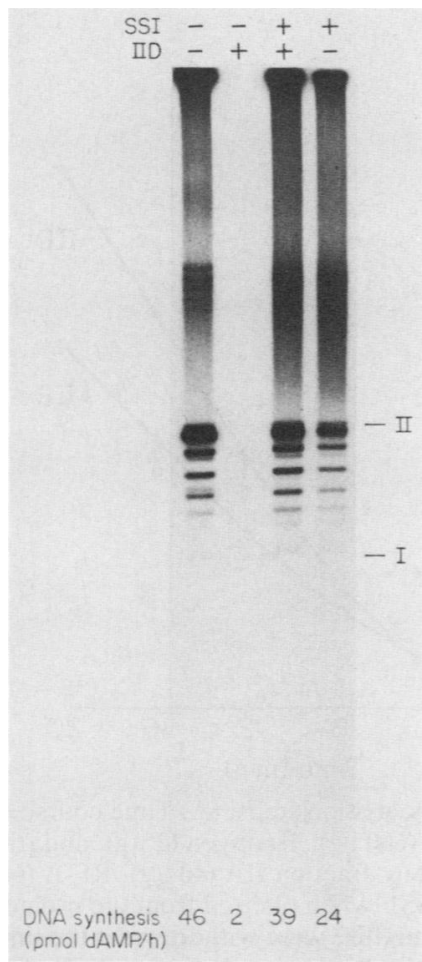

FIG. 5. Inhibition of SV40 replication in vitro with fraction IID and neutralization of the inhibition with fraction SSI. Replication reactions were performed as described in Materials and Methods, except for the addition of fraction IID $(16 \mu \mathrm{g})$ and/or fraction SSI $(120 \mu \mathrm{g})$ to the complete system as indicated. After $1 \mathrm{~h}$ of incubation at $37^{\circ} \mathrm{C}$, acid-insoluble counts in a sample of these reaction mixtures were measured and are indicated below the autoradiograph. The replication products were purified, and an equal portion of each was loaded into a neutral agarose gel. The positions of forms I and II of the template DNA are indicated.

formed in the presence or absence of fraction IID. When fraction IID was preincubated with the SV40 origin DNA and $T$ antigen, subsequent DNA synthesis was completely blocked. When fraction SSI was also included in the preincubation, however, a normal reduced time lag was observed (Fig. 6A). In another experiment, $T$ antigen and DNA were first preincubated and then IID and the other replication components were added at time zero. Initiation of DNA synthesis and elongation occurred almost normally (i.e., with a reduced time lag), showing that fraction IID had no effect on the kinetics of DNA replication after T antigen and template DNA were preincubated together (Fig. 6B). Therefore, the inhibition and neutralization mechanism by fractions IID and SSI, respectively, seems to be specific for the first step in the presynthesis stage of replication, formation of the $\mathrm{T}$ complex. That is, fraction IID inhibits the formation of a complex between T antigen and SV40 ori, but does not affect subsequent stages of replication.

\section{DISCUSSION}

DNA replication from the SV40 origin sequence has been reconstituted with a number of purified cell-encoded replication proteins and the SV40 T antigen. One fraction (fraction IIA), however, is not purified and contains multiple replication factors, including DNA polymerases (T. Tsurimoto and B. Stillman, unpublished results). Product analy- ses revealed that authentic and complete DNA replication was achieved in this system, although the efficiency of DNA synthesis was about two- to threefold lower than that previously reported with less highly purified components $(36,48)$. This may be due to the loss of nonessential stimulatory factors which have been separated from the essential components by fractionation. For example, if purified PCNA is replaced with the less highly purified fraction $B$ (Fig. 1), the amount of DNA replication is enhanced $(20,36$; data not shown). The nature and significance of these stimulatory factors remain to be established.

Multiple stages of initiation. The results presented here and elsewhere lead to the conclusion that SV40 DNA replication can be separated into multiple stages. Interestingly, there appear to be at least three distinct stages prior to the actual start of DNA synthesis. Kinetic analyses of DNA replication and origin unwinding, with and without a preincubation of selected replication factors and template DNA (Fig. 3 and 4), suggest that origin recognition and unwinding involve at least two stages of replication. These results are discussed in the context of a model for initiation of replication (Fig. 7), which is based on a similar model for initiation of replication at the $E$. coli oriC and phage $\lambda$ replication origins (see references $7,8,17$, and 39 for reviews). In this model, the first step in replication is the ATP-dependent recognition by $\mathrm{T}$ antigen of its binding site II within the core origin to form the $\mathrm{T}$ complex. Boroweic and Hurwitz (4) have demonstrated that $\mathrm{T}$-antigen binding to site $\mathrm{II}$ in the presence of ATP causes local unwinding of the early palindrome region within the origin and induction of an altered conformation in the A+T-rich region. This ATP-dependent reaction has been extensively characterized and involves the assembly of an oligomeric complex of $\mathrm{T}$ antigen at the origin $(4,5,13,14$, 37a). This step may actually involve two substeps for $T$ complex formation, one requiring ATP and the other requiring ATP hydrolysis $(4,37 a)$.

A second proposed stage of initiation is the formation of the unwound complex, which requires the cellular protein RF-A. For reasons outlined below, we distinguish between the unwound complex, which is proposed to be a direct intermediate in the coordinated events of unwinding of the origin and primer formation, and the production of a highly underwound molecule, form $U$, which occurs in the absence of DNA replication. In the next step of replication, we propose the formation of a priming complex at the origin, which requires unidentified replication factors present in fraction IIA. This complex is the immediate precursor of primer formation and origin-specific DNA synthesis, presumably by the DNA polymerase $\alpha$-DNA primase complex. Subsequent bidirectional DNA synthesis from the origin may require two DNA polymerases, $\alpha$ and $\delta$.

The full time lag in the replication reaction (Fig. 3) would represent the time taken to assemble the priming complex when replication reaction mixtures are shifted from 0 to $37^{\circ} \mathrm{C}$, i.e., without any preincubation step at all. If $\mathrm{T}$ antigen and the template DNA are preincubated for $15 \mathrm{~min}$ at $37^{\circ} \mathrm{C}$ before the other replication components are added, the $\mathrm{T}$ complex could form, resulting in a shorter time lag before DNA synthesis occurs (Fig. 3). Formation of the T complex also eliminates any time lag in the rate of accumulation of form $U$ (Fig. 4). Note that elimination of the time lag for form $\mathrm{U}$ production when $\mathrm{T}$ antigen is preincubated with the template DNA (ca. 5 min [Fig. 4]) is analogous to the shift from a full time lag (ca. $10 \mathrm{~min}$ ) to a reduced time lag (ca. 5 min) for DNA replication (Fig. 3). Following formation of the $T$ complex and addition of the other replication compo- 
A

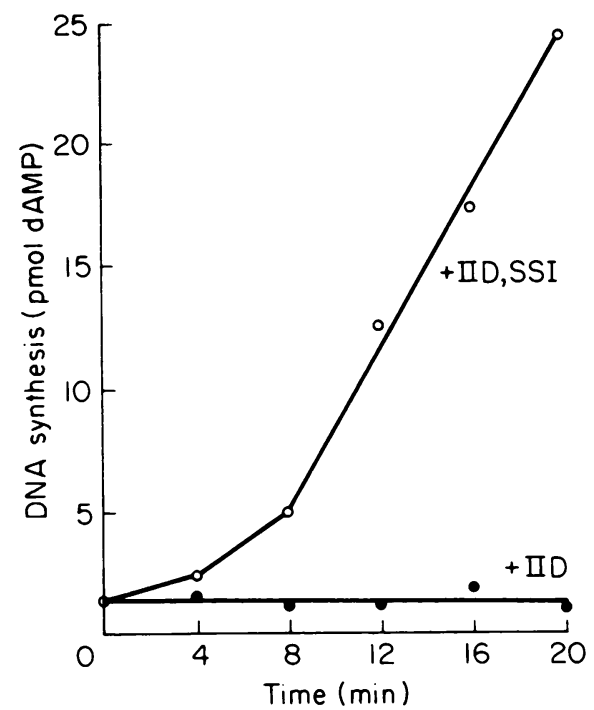

B

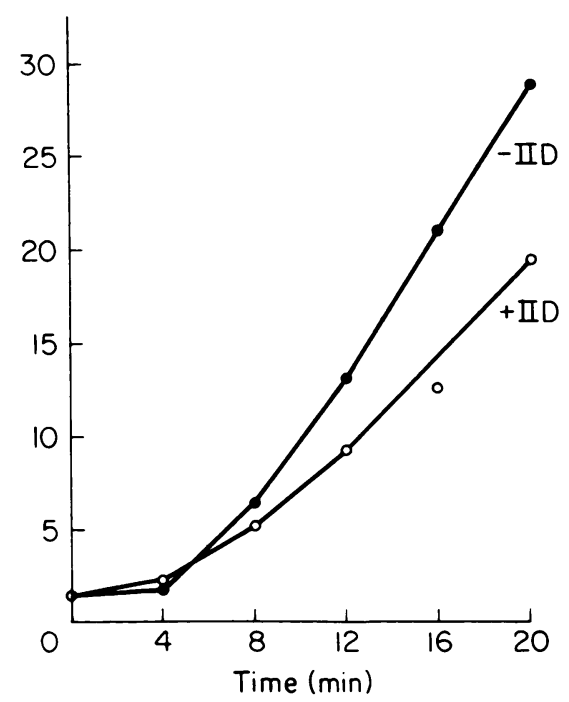

FIG. 6. Effect of fractions SSI and IID on the kinetics of DNA synthesis following preincubation steps. (A) Time course of DNA synthesis following a $15-\mathrm{min}$ preincubation at $37^{\circ} \mathrm{C}$ in $100 \mu \mathrm{l}$ of reaction mixture containing pSVO10 $(600 \mathrm{ng})$, T antigen $(2 \mu \mathrm{g})$, and fraction IID (32 $\left.\mu \mathrm{g}\right)$ in the presence $(O)$ or absence $(O)$ of fraction SSI $(260 \mu \mathrm{g})$. Following the preincubation step, fraction IIA $(40 \mu \mathrm{g})$, RF-A (600 ng), RF-C (200 ng), PCNA (300 ng), topoisomerases I and II (400 and $180 \mathrm{ng}$, respectively), and fraction SSI (when omitted from the preincubation reaction) were added at time zero with the deoxynucleoside triphosphates. Portions of the reaction mixture were withdrawn at the times indicated, and the acid-insoluble counts were measured. (B) Time course of DNA synthesis following a 15-min preincubation at $37^{\circ} \mathrm{C}$ of reaction mixtures $(100 \mu \mathrm{l})$ containing pSVO10 $(600 \mathrm{ng})$ and T antigen $(2 \mu \mathrm{g})$. At time zero, fraction IIA, RF-A, RF-C, PCNA, and topoisomerases I and II were added (as in panel A) with $(O)$ or without $(\Theta)$ fraction IID. Portions were withdrawn at the indicated times, and the acid-insoluble counts were measured.

nents, a reduced time lag (ca. $5 \mathrm{~min}$ ) occurs before the onset of DNA replication. We propose that this is due to the time taken to accumulate the unwound complex from the preformed T complex (Fig. 3). Once the unwound complex is formed, the initial rate of DNA synthesis is linear with time (Fig. 3), and we propose that this is due to the simple rate of accumulation of the priming complex. Thus, the data shown in Fig. 3 and 4 can be explained in terms of the accumulation of a series of DNA-protein complexes during the presynthesis stage of replication. This model of the presynthesis stage of replication is also consistent with the previously described ATP-dependent formation of an oligomeric T-antigen complex at the origin $(4,5,13,14)$ and the involvement of RF-A in form $\mathrm{U}$ production. Although others have measured the production of form $U$ after a $2-h$ incubation (12), the data in Fig. 4 show that following the assembly of the $T$ complex, form $U$ production can occur rapidly in the presence of RF-A.

The fact that extensive unwinding of the template DNA can occur in the absence of DNA replication creates a problem for replication control in vivo. If $T$ antigen and RF-A could recognize the origin and extensively unwind the template DNA in the absence of DNA replication, a large amount of single-stranded DNA would accumulate. This would be detrimental to DNA replication and transcription and would compromise the growth of the virus. Similarly, unwinding from cellular origins in the absence of DNA replication would cause problems for genome integrity. Therefore, origin unwinding and the initiation of DNA synthesis at the origin must be coupled events, and we suggest that a mechanism exists in the cell to prevent extensive unwinding without concomitant DNA synthesis.

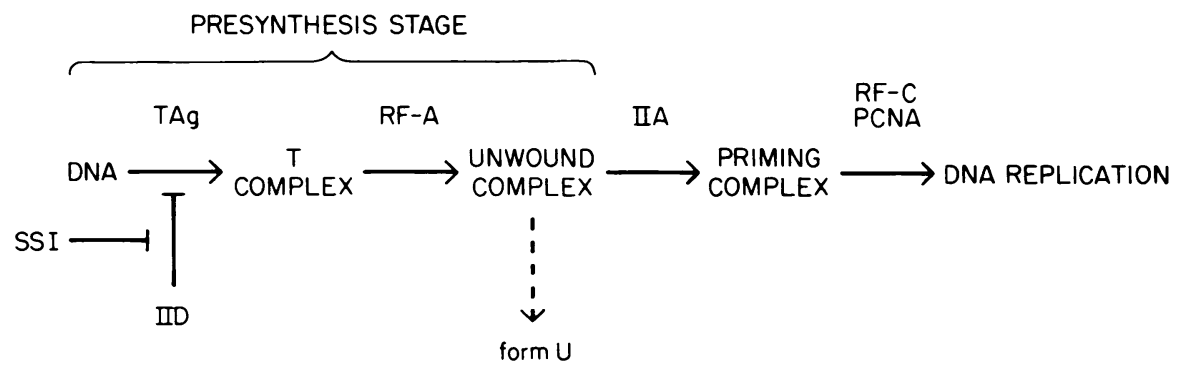

FIG. 7. Model for the multiple stages of initiation of replication from the SV40 origin. The first stage, formation of the T complex, corresponds to the ATP-dependent formation of an oligomeric complex of T antigen (TAg) at the origin. The addition of RF-A forms the unwound complex. If origin unwinding is not coupled to DNA replication, extensive unwinding yields form U DNA (-- - $\rightarrow$ ). If unwinding of the origin is coupled to DNA replication, a priming complex is formed which is the direct precursor complex for primer formation at the origin and DNA synthesis. Fraction IID inhibits T-complex formation, and fraction SSI antagonizes this inhibition. 
This mechanism could operate at any point during the presynthesis stage of replication shown in Fig. 7 and may even be related to the mechanism of activation of replication origins in cellular chromosomes during the $S$ phase of the cell cycle.

Inhibition of T-complex formation. Fractions IID and SSI are not essential for DNA replication in vitro in the most highly purified system, but in the presence of fraction IID, fraction SSI is absolutely required. Inhibition by fraction IID is limited to formation of the $T$ complex, since once $T$ antigen and the template DNA have been preincubated in the presence of ATP, subsequent addition of fraction IID has little effect on the initial reaction kinetics, even in the absence of fraction SSI (Fig. 6B). A protein(s) present in fraction IID might inhibit the interaction of $\mathrm{T}$ antigen with DNA or prevent local opening of the early palindrome or alteration in the conformation of the $\mathrm{A}+\mathrm{T}$-rich sequence, all of which lead to T-complex formation $(4,5,14)$.

Roberts and D'Urso (38) have described an interesting result related to cell cycle regulation of DNA replication. It was shown that extracts prepared from cells enriched in the G1 phase of the cell cycle were essentially inactive for form $\mathrm{U}$ production and DNA replication, whereas extracts prepared from $S$ and $G 2$ phase-enriched cells were active. In an attempt to determine which factor was cell cycle regulated, they added either RF-A or topoisomerase to the G1-specific extracts, but neither of these proteins caused the G1 extracts to support form U production. Since RF-A and topoisomerase are the only cellular proteins required for form $U$ production in the purified system (Fig. 4), and since the amount of these proteins did not vary throughout the cell cycle (S. Din and B. Stillman, unpublished observations), the cell-cycle-specific unwinding in crude extracts remains enigmatic. One possibility that must now be considered is that the inhibitory activity of fraction IID is constitutive throughout the cell cycle and is therefore present in G1, S, and $\mathrm{G} 2$ extracts but that the activity in fraction SSI that antagonizes the IID inhibition is present only in S and G2 extracts. This explanation would conform to the expectation that a positive factor is influencing the replication in S-phase extracts (38) and may provide an explanation for the cell cycle results. It is clear that further work is needed to determine the difference between the G1- and S-phase extracts and whether the activities present in fractions IID and SSI contribute to this difference. Additionally, the significance of the IID inhibition in vivo must be addressed.

Elongation stages of DNA replication. Once the unwound complex is formed, the initiation of DNA replication depends upon the partially purified fraction IIA. This fraction contains multiple essential replication factors, including the polymerase $\alpha$-DNA primase complex and other polymerase and replication activities ( $T$. Tsurimoto, T. Melendy, and B. Stillman, unpublished observations). DNA replication in the presence of fraction IIA alone is limited to the production of short nascent DNA strands that derive predominantly from the lagging-strand template and origin-specific products that remain bound to the template. These products are similar to those previously described when replication was supported by crude extracts that lacked either PCNA (37) or RF-C (48). Furthermore, in the reconstituted system the addition of PCNA and RF-C is required for complete DNA replication. Thus, the elongation stage of DNA replication in this semipurified system reflects the mechanism of coordinated leading- and lagging-strand replication demonstrated previously. Since PCNA is a processivity factor for DNA polymerase $\delta$ $(35,47)$, it is likely that polymerase $\delta$ is in fraction IIA and is required for synthesis of the leading strand at a replication fork.

Recently, a reconstituted system that supported DNA synthesis from the SV40 origin and that did not require PCNA, RF-C, or DNA polymerase $\delta$ was described (22). The mechanism of DNA replication, however, appeared to be different from the mechanism reported here, because the polymerase $\alpha$-primase complex supported DNA synthesis on both leading and lagging strands and, more importantly, DNA replication was very inefficient when compared with replication in crude extracts. The lack of requirement for PCNA was attributed to the removal from the crude extracts of an inhibitor of chain elongation (26). PCNA was reported to overcome this inhibitor, but, in addition, PCNA-dependent replication could be restored only if a crude fraction (probably similar to fraction IIA) and other activators were added. It is possible that one of these activators is RF-C. The significance of the inhibitor is not clear. On the basis of its chromatographic properties on a phosphocellulose resin, the inhibitor should not be present in the reconstituted system described herein. We also note that the inhibitor activity in fraction IID is not the same as the inhibitor described by Lee et al. (26), because they affect different stages of replication.

The reconstitution of SV40 DNA replication with purified replication proteins should enable the mechanism of replication to be investigated in detail, but also should usher in new approaches and generate valuable reagents that are needed to understand the mechanism and control of cellular DNA replication. However, it is clear that the results obtained in vitro must be followed up to see whether they have significance in vivo. In this regard, the recent identification of a DNA polymerase $\delta$-like enzyme and a PCNA equivalent in the yeast Saccharomyces cerevisiae $(2,3,10)$ offers the opportunity of a genetic approach to the problem and suggests that studying SV40 DNA replication in vitro provides an excellent model for cellular DNA replication.

\section{ACKNOWLEDGMENTS}

We thank Bruce Futcher, Carol Greider, Tom Melendy, and Susan Smith for helpful discussions and critism of draft manuscripts; Shirley Longionetti for technical assistance; and Barbara Weinkauff for typing.

The work described herein was supported by Public Health Service grant CA13106 from the National Institutes of Health. T.T. was a fellow of the Long Island Biological Society.

\section{LITERATURE CITED}

1. Alberts, B. M., J. Barry, P. Bedinger, T. Formosa, C. V. Jongeneel, and K. N. Kreuzer. 1982. Studies on DNA replication in the bacteriphage T4 in vitro system. Cold Spring Harbor Symp. Quant. Biol. 47:655-668.

2. Bauer, G. A., and P. M. J. Burgers. 1988. The yeast analog of mammalian cyclin/proliferating-cell nuclear antigen interacts with mammalian DNA polymerase $\delta$. Proc. Natl. Acad. Sci. USA 85:7506-7510.

3. Bauer, G. A., H. M. Heller, and P. M. J. Burgers. 1988. DNA polymerase III from Saccharomyces cerevisiae. I. Purification and characterization. J. Biol. Chem. 263:917-924.

4. Boroweic, J. A., and J. Hurwitz. 1988. Localized melting and structural changes in the SV40 origin of replication induced by T antigen. EMBO J. 7:3149-3158.

5. Borowiec, J. A., and J. Hurwitz. 1988. ATP stimulates the binding of simian virus 40 (SV40) large tumor antigen to the SV40 origin of replication. Proc. Natl. Acad. Sci. USA 85: $64-68$.

6. Bradford, M. M. 1976. A rapid and sensitive method for the quantitation of microgram quantities of protein utilizing the 
principle of protein dye binding. Anal. Biochem. 72:248-254.

7. Bramhill, D., and A. Kornberg. 1988. A model for initiation at origins of DNA replication. Cell 54:915-918.

8. Bramhill, D., and A. Kornberg. 1988. Duplex opening by dnaA protein at novel sequences in initiation of replication at the origin of the $E$. coli chromosome. Cell 52:743-755.

9. Bravo, R., R. Frank, P. A. Blundell, and H. MacDonald-Bravo. 1987. Cyclin/PCNA is the auxiliary protein of DNA polymerase$\delta$. Nature (London) 326:515-517.

10. Burgers, P. M. J. 1988. Mammalian cyclin/PCNA (DNA polymerase $\delta$ auxiliary protein) stimulates processive DNA synthesis by yeast DNA polymerase III. Nucleic Acids Res. 16: 6297-6306.

11. Byrnes, J. J., K. M. Downey, V. L. Black, and A. G. So. 1976. A new mammalian DNA polymerase with $3^{\prime}$ to $5^{\prime}$ exonuclease activity: DNA-polymerase $\delta$. Biochemistry 15:2817-2823.

12. Dean, F. B., P. Bullock, Y. Murakami, C. R. Wobbe, L. Weissbach, and J. Hurwitz. 1987. Simian virus 40 (SV40) DNA replication: SV40 large $T$ antigen unwinds DNA containing the SV40 origin of replication. Proc. Natl. Acad. Sci. USA 84: 16-20.

13. Dean, F. B., M. Dodson, H. Echols, and J. Hurwitz. 1987. ATP-dependent formation of a specialized nucleoprotein structure by simian virus 40 (SV40) large tumor antigen at the SV40 replication origin. Proc. Natl. Acad. Sci. USA 84:8981-8985.

14. Deb, S. P., and P. Tegtmeyer. 1987. ATP enhances the binding of simian virus 40 large $T$ antigen to the origin of replication. $J$. Virol. 61:3649-3654.

15. DePamphilis, M. L., and M. K. Bradley. 1986. Replication of SV40 and polyoma virus chromosomes, p. 99-246. In N. P. Salzman (ed.), The Papovaviridae. Plenum Publishing Corp., New York.

16. Dodson, M., F. B. Dean, P. Bullock, H. Echols, and J. Hurwitz. 1987. Unwinding of duplex DNA from the SV40 origin of replication by $T$ antigen. Science 238:946-967.

17. Dodson, M., H. Echols, S. Wickner, C. Alfano, K. MensaWilmot, B. Gomes, J. LeBowitz, J. D. Roberts, and R. McMacken. 1986. Specialized nucleoprotein structures at the origin of replication of bacteriophage $\lambda$ : localized unwinding of duplex DNA by a six-protein reaction. Proc. Natl. Acad. Sci. USA 83:7638-7642.

18. Downey, K. M., C. K. Tan, D. M. M. Andrews, X. Li, and A. G. So. 1988. Proposed roles for DNA polymerases alpha and delta at the replication fork. Cancer Cells 6:1211-1218.

19. Fairman, M. P., G. Prelich, and B. Stillman. 1987. Identification of multiple cellular factors required for SV40 replication in vitro. Phil. Trans. R. Soc. London Ser. B 317:495-505.

20. Fairman, M. P., and B. Stillman. 1988. Cellular factors required for multiple stages of SV40 replication in vitro. EMBO J. 7:1211-1218.

21. Goetz, G. S., F. B. Dean, J. Hurwitz, and S. W. Matson. 1988 The unwinding of duplex regions in DNA by the simian virus 40 large tumor antigen-associated DNA helicase activity. J. Biol. Chem. 263:383-392.

22. Ishimi, Y., A. Claude, P. Bullock, and J. Hurwitz. 1988. Complete enzymatic synthesis of DNA containing the SV40 origin or replication. J. Biol. Chem. 263:19723-19733.

23. Kornberg, A. 1982. DNA replication. Supplement. W. H. Freeman, San Francisco.

24. Laemmli; U. K. 1970. Cleavage of structural proteins during the assembly of the head of bacteriophage T4. Nature (London) 227:680-685.

25. Lanford, R. E. 1988. Expression of simian virus $40 \mathrm{~T}$ antigen in insect cells using a baculovirus expression vector. Virology 167:72-81.

26. Lee, S.-H., Y. Ishimi, M. K. Kenny, P. Bullock, F. B. Dean, and J. Hurwitz. 1988. An inhibitor of the in vitro elongation reaction of simian virus 40 DNA replication is overcome by proliferating cell nuclear antigen. Proc. Natl. Acad. Sci. USA 85:9469-9473.

27. Li, J. J., and T. J. Kelly. 1984. Simian virus 40 DNA replication in vitro. Proc. Natl. Acad. Sci. USA 81:6973-6977.

28. Li, J. J., and T. J. Kelly. 1985. Simian virus 40 DNA replication in vitro: specificity of initiation and evidence for bidirectional replication. Mol. Cell. Biol. 5:1238-1246.

29. Liu, L. F., and K. G. Miller. 1981. Eukaryotic DNA topoisomerases: two forms of type I DNA topoisomerases from HeLa cells nuclei. Proc. Natl. Acad. Sci. USA 78:3487-3491.

30. Maniatis, T., E. F. Fritsch, and J. Sambrook. 1982. Molecular cloning: a laboratory manual. Cold Spring Harbor Laboratory, Cold Spring Harbor, N.Y.

31. McHenry, C. S. 1988. DNA polymerase III holoenzyme of Escherichia coli. Annu. Rev. Biochem. 57:519-550.

32. Murakami, Y., C. R. Wobbe, L. Weissbach, F. B. Dean, and J. Hurwitz. 1986. Role of DNA polymerase $\alpha$ and DNA primase in simian virus 40 DNA replication in vitro. Proc. Natl. Acad. Sci. USA 83:2869-2873.

33. Nakai, H., and C. C. Richardson. 1988. Leading and lagging strand synthesis at the replication fork of bacteriophage $\mathrm{T} 7$. Distinct properties of $\mathrm{T} 7$ gene 4 protein as a helicase and primase. J. Biol. Chem. 263:9818-9830.

34. Ogawa, T., and T. Okazaki. 1980. Discontinuous DNA replication. Annu. Rev. Biochem. 49:421-457.

35. Prelich, G., C. K. Tan, M. Kostura, M. B. Mathews, A. G. So, K. Downey, and B. Stillman. 1987. Functional identity of proliferating cell nuclear antigen and a DNA polymerase- $\delta$ auxiliary protein. Nature (London) 326:517-520.

36. Prelich, G., M. Kostura, D. R. Marshak, M. B. Mathews, and B. Stillman. 1987. The cell-cycle regulated proliferating cell nuclear antigen is required for SV40 DNA replication in vitro. Nature (London) 326:471-475.

37. Prelich, G., and B. Stillman. 1988. Coordinated leading and lagging strand synthesis during SV40 DNA replication in vitro requires PCNA. Cell 53:117-126.

37a.Roberts, J. M. 1989. SV40 T antigen causes step wise changes in SV40 origin structure during the initiation of DNA replication. Proc. Natl. Acad. Sci. USA 86:3939-3943.

38. Roberts, J. M., and G. D'Urso. 1988. An origin unwinding activity regulates initiation of DNA replication during mammalian cell cycle. Science 241:1486-1489.

39. Schnos, M., K. Zahn, R. B. Inman, and F. R. Blattner. 1988. Initiation protein induced helix destabilization at the $\lambda$ origin: a pre-priming step in DNA replication. Cell 52:385-395.

40. Schomburg, V., and F. Grosse. 1986. Purification and characterization of DNA topoisomerase II from calf thymus associated with polypeptides of 175 and $150 \mathrm{KDa}$. Eur. J. Biochem. 160:451-457.

41. Simanis, V., and D. P. Lane. 1985. An immunoaffinity purification procedure for SV40 large T antigen. Virology 144:88100.

42. So, A. G., and K. M. Downey. 1988. Mammalian DNA polymerase $\alpha$ and $\delta$ : current status in DNA replication. Biochemistry 27:4591-4595.

43. Stahl, H., P. Dröge, and R. Knippers. 1986. DNA helicase activity of SV40 large tumor antigen. EMBO J. 5:1939-1944.

44. Stillman, B. 1989. Initiation of eukaryotic DNA replication. Annu. Rev. Cell Biol. 5:197-245.

45. Stillman, B., J. F. X. Diffley, G. Prelich, and R. A. Guggenheimer. 1986. DNA-protein interactions at the replication origins of adenovirus and SV40. Cancer Cells 4:453-463.

46. Stillman, B. W., and Y. Gluzman. 1985. Replication and supercoiling of simian virus $40 \mathrm{DNA}$ in cell extracts from human cells. Mol. Cell. Biol. 5:2051-2060.

47. Tan, C. K., C. Castillo, A. G. So, and K. M. Downey. 1986. An auxiliary protein for DNA polymerase- $\delta$ from fetal calf thymus. J. Biol. Chem. 261:12310-12316.

48. Tsurimoto, T., and B. Stillman. 1989. Purification of a cellular replication factor, RF-C, that is required for coordinated synthesis of leading and lagging strands during simian virus 40 DNA replication in vitro. Mol. Cell. Biol. 9:609-619.

49. Wiekowski, M., M. W. Schwarz, and H. Stahl. 1988. Simian virus 40 large $T$ antigen DNA helicase. Characterization of the ATP-ase-dependent DNA unwinding activity and its substrate requirements. J. Biol. Chem. 263:436-442.

50. Wobbe, C. R., F. B. Dean, Y. Murakami, L. Weissbach, and J. Hurwitz. 1986. Simian virus 40 DNA replication in vitro: study of events preceding elongation of chains. Proc. Natl. Acad. Sci. 
USA 83:4612-4616.

51. Wobbe, C. R., F. Dean, L. Weissbach, and J. Hurwitz. 1985. In vitro replication of duplex circular DNA containing the simian virus 40 DNA origin site. Proc. Natl. Acad. Sci. USA 82: 5710-5714.

52. Wobbe, C. R., L. Weissbach, J. A. Borowiec, F. B. Dean, Y. Murakami, P. Bullock, and J. Hurwitz. 1987. Replication of simian virus 40 origin-containing DNA in vitro with purified proteins. Proc. Natl. Acad. Sci. USA 84:1834-1838.

53. Wold, M. S., and T. J. Kelly. 1988. Purification and characterization of replication protein A, a cellular protein required for in vitro replication of simian virus 40 DNA. Proc. Natl. Acad. Sci. USA 85:2523-2527.
54. Wold, M. S., J. J. Li, and T. J. Kelly. 1987. Initiation of simian virus 40 DNA replication in vitro: large-tumor-antigen and origin-dependent unwinding of the template. Proc. Natl. Acad. Sci. USA 84:3643-3647.

55. Wray, W., T. Boulikas, V. P. Wray, and R. Hancock. 1981. Silver staining of proteins in polyacrylamide gels. Anal. Biochem. 118:197-203.

56. Yang, L., M. S. Wold, J. J. Li, T. J. Kelly, and L. F. Liu. 1987. Roles of DNA topoisomerases in simian virus 40 DNA replication in vitro. Proc. Natl. Acad. Sci. USA 84:950-954.

57. Zuber, M., E. M. Tan, and M. Ryoji. 1989. Involvement of proliferating cell nuclear antigen (cyclin) in DNA replication in living cells. Mol. Cell. Biol. 9:57-66. 